\section{GLOSSARY OF TERMS FOR PROBABILISTIC SEISMIC-RISK AND HAZARD ANALYSIS}

Bulletin Editor's Note: This glossary is the work of the EERI Committee on Seismic Risk. It was published in Earthquake Spectra, Vol. 1, No. 1, November 1984, and it is reprinted here with the permission of EERI.

Probabilistic seismic hazard and risk analysis methods have been routinely used for the last 10 years. During these years it has become increasingly clear that a standard terminology should be prepared for use by all the researchers, teachers and users. Improper and ambiguous use of terms has led to some confusion in the past.

In 1977, the EERI Committee on Seismic Risk was assigned the task of developing a terminology in the form of a glossary of terms. The proposed "Glossary of Terms" for Probabilistic Seismic Risk and Hazard Analysis" was first developed over a fiveyear period between 1977 and 1982. During this period, the proposal has gone through various reviews by the Committee as well as by the membership of EERI. In 1981, a draft of the present glossary was published in the Newsletter and the resulting comments from the readers have been incorporated in the present document.

The glossary presented here should be considered as a trial basis for use by the profession. Compilation and use of such a glossary should be viewed as a dynamic process. It should be reviewed, corrected, and updated every three to five years. If during any such review the practitioners find that additional widely used terms should be included, then the Committee will address that question and will revise or update the glossary.

The present glossary was compiled by the Earthquake Engineering Research Institute Committee on Seismic Risk under the chairmanship of Haresh C. Shah. Particular acknowledgement should be made to the contributions made by Robin McGuire (who is the current chair of the Committee) Walter Hays, Bruce Bolt, Roger Scholl, and David Leeds. The following members of the Committee participated in the development and compilation of this glossary.

Auld, B.C.

Kiremidjian, A.S.

Algermissen, S.T. Kustu, O.

Bolt, B.A. Lefter, J.

Cluff, L.S.

Cornell, C.A.

Donovan, N.C.

Eguchi, R.T.

Escalante, L.E.

Fox, R.R.

Freeman, S

Greenlaw, R.W.

Gulliver, R.M.

Howe, $W$.

Howell, B.J. Jr.

Hunt, G.S.

Johnson, J.A.

\section{GLOSSARY OF TERMS}

ACCEPTABLE RISK - a probability of social or economic consequences due to earthquakes that is low enough (for example in comparison with other natural or manmade risks) to be judged by appropriate authorities to represent a realistic basis for determining design requirements for engineered structures, or for taking certain social or economic actions.

ACTIVE FAULT - a fault that on the basis of historical, seismological, or geological evidence has a high probability of producing an earthquake. (Alternate: a fault that may produce an earthquake within a specified exposure time, given the assumptions adopted for a specific seismic-risk analysis).

ATTENUATION LAW - a description of the behaviour of a characteristic of earthquake ground motion as a function of the distance from the source of energy.

B-VALUE - a parameter indicating the relative frequency of occurrence of earthquakes of different sizes. It is the slope of a straight line indicating absolute or relative frequency (plotted logarithmically) versus earthquake magnitude or meizoseismal Modified Mercalli intensity. (The Bvalue indicates the slope of the Gutenberg-Richter recurrence relationship).

COEFFICIENT OF VARIATION - the ratio of standard deviation to the mean.

DAMAGE - any economic loss or destruction caused by earthquakes.

DESIGN ACCELERATION - a specification of the ground acceleration at a site, terms of a single value such as the peak or rms; used for the earthquakeresistant design of a structure for as a base for deriving a design spectrum). See "Design Time History."

DESIGN EARTHQUAKE - a specification of the seismic ground motion at a site; used for the earthquake-resistant design of a structure.

DESIGN EVENT, DESIGN SEISMIC EVENT - a specification of one or more earthquake source parameters, and of the location of energy release with respect to the site of interest; used for the earthquake-resistant design of a structure.

DESIGN GROUND MOTION - see "Design Earthquake."

DESIGN SPECTRUM - a set of curves for design purposes that gives acceleration velocity, or displacement (usually absolute acceleration. relative velocity, and relative displacement of the vibrating mass, as a function of period of vibration and damping. 
DESIGN TIME HISTORY - the variation with time of ground motion (e.g., ground acceleration or velocity or displacementl at a site; used for the earthquake-resistant design of a structure. See "Design Acceleration".

DURATION - a qualitative or quantitative description of the length of time during which ground motion at a site shows certain characteristics (perceptibility, violent shaking, etc.).

EARTHOUAKE - a sudden motion or vibration in the earth caused by the abrupt release of energy in the earth's lithosphere. The wave motion may range from violent at some locations to imperceptible at others.

ELEMENTS AT RISK - population, properties, economic activities, including public services etc., at risk in a given area.

EXCEEDANCE PROBABILITY - the probability that a specified level of ground motion or specified social or economic consequences of earthquakes, will be exceeded at a site or in a region during a specified exposure time.

EXPECTED - mean, average.

EXPECTED GROUND MOTION - the mean value of one or more characteristics of ground motion at a site for a single earthquake. (Mean ground motion.)

EXPOSURE - the potential economic loss to all or a certain subset of structures as a result of one or more earthquakes in an area. This term usually refers to the insured value of structures carried by one or more insurers. See "Value at Risk."

EXPOURE TIME - the time period of interest for seismic-risk calculations, seismichazard calculations, or design of structures. For structures, the exposure time is often chosen to be equal to the design lifetime of the structure.

GEOLOGIC HAZARD - a geologic process (e.g., landsliding, liquefaction soils, active faulting) that during an earthquake or other natural event may produce adverse effects in structures.

INTENSITY - a qualitative or quantitative measure of the severity of seismic ground motion at a specific site (e.g., Modified Mercalli intensity, RossiForel intensity, Housner spectral intensity, Arias intensity, peak acceleration, etc.).

LOSS - any adverse economic value attained by a variable during a specified exposure time. See "Peak Value."

MAXIMUM CREDIBLE MAXIMUM EXPECTABLE

MAXIMUM EXPECTED MAXIMUM PROBABLE

These terms are used to specify the largest value of a variable. for example, the magnitude of an earthquake, that might reasonably be expected to occur. In the Committee's view, these are misleading terms and their use is discouraged.

The U.S. Geological survey and some individuals and companies define the maximum credible earthquake as "the largest earthquake that can be reasonably expected to occur." The Bureau of Reclamation, the First Interagency Working Group (Sept. 1978) defined the maximum credible earthquake as "the earthquake that would cause the most severe vibratory ground motion capable of being produced at the site under the current known tectonic framework." It is an event that can be supported by all known geologic and seismologic data. The maximum expectable or expected earthquake is defined by USGS as "the largest earthquake that can be reasonably expected to occur." The maximum probable earthquake is sometimes defined as the worst historic earthquake. Alternatively, it is defined as the 1.00-year-returnperiod earthquake, or an earthquake that by probabilistic determination of recurrence will take place during the life of a structure.)

MAXIMUM POSSIBLE - the largest value possible for a variable. This follows from an explicit assumption that larger values are not possible, or implicitly from assumptions that related variables or functions are limited in range. The maximum possible value may be expected deterministically or probabilistically.

MEAN RECURRENCE INTERVAL, AVERAGE RECURRENCE INTERVAL - the average time between earthquakes or faulting events with specific characteristics (e.g. magnitude $\geq 6$ ) in a specified region or in a specified fault zone.

MEAN RETURN PERIOD - the average time between occurrence of ground motion with specific characteristics (e.g. peak horizontal acceleration $\geq 0.1 \mathrm{~g}$ ) at a site. (Equal to the inverse of the annual probability of exceedance.)

MEAN SQUARE - expected value of the square of the random variable. (Mean square minus square of the mean gives the variance of random variable.)

PEAK VALUE - the largest value of a timedependent variable during an earthquake.

RESPONSE SPECTRUM - a set of curves calculated from an earthquake accelerogram that gives values of peak response of a damped linear oscillator, as a function of its period of vibration and damping.

ROOT MEAN SQUARE (rms) - square root of the mean square value of a random variable.

SEISMIC-ACTIVITY RATE - the mean number per unit time of earthquakes with specific characteristics (e.g., magnitude $\geq 6$ ) originating on a selected fault or in a selected area. 
SEISMIC-DESIGN-LOAD EFFECTS - the actions (axial forces, shears, or bending moments) and deformations induced in a structural system due to a specified representation (time history. response spectrum, or base shear) of seismic design ground motion.

SEISMIC-DESIGN LOADING - the prescribed representation (time history, response spectrum, or equivalent static base shear) of seismic ground motion to be used for the design of a structure.

SEISMIC-DESIGN ZONE - seismic zone.

SEISMIC EVENT - the abrupt release of energy in the earth's lithosphere, causing an earthquake.

SEISMIC HAZARD - any physical phenomenon (e.g., ground shaking, ground failure) associated with an earthquake that may produce adverse effects on human activities.

SEISMIC RISK - the probability that social or economic consequences of earthquakes will equal or exceed specified values at a site, at several sites, or in an area, during a specified exposure time.

SEISMIC-RISK ZONE - an obsolete term. See "Seismic Zone."

SEISMIC-SOURCE ZONE - an obsolete term. See "Seismogenic Zone" and "Seismotectonic Zone."

SEISMIC ZONE - a generally large area within which seismic-design requirements for structures are constant.

SEISMIC ZONING, SEISMIC ZONATION - the process of determining seismic hazard at many sites for the purpose of delineating seismic zones.

SEISMIC MICROZONE - a generally small area within which seismic-design requirements for structures are uniform. Seismic microzones may show relative ground motion amplification due to local soil conditions without specifying the absolute levels of motion or seismic hazard.

SEISMIC MICROZONING, SEISMIC MICROZONATION the process of determining absolute or relative seismic hazard at many sites, accounting for the effects of geologic and topographic amplification of motion and of soil stability and liquefaction, for the purpose of delineating seismic microzones. Alternatively, microzonation is a process for identifying detailed geological, seismological, hydrological, and geotechnical site characteristics in a specific region and incorporating them into land-use planning and the design of safe structures in order to reduce damage to human life and property resulting from earthquakes.
Iithosphere in which earthquakes are inferred to be of similar tectonic origin. A seismogenic zone may represent a fault in the earth's lithosphere. See "Seismotectonic Zone."

SEISMOGENIC ZONING - the process of delineating regions having nearly homogeneous tectonic and geologic character, for the purpose of drawing seismogenic zones. The specific procedures used depend on the assumptions and mathematical models used in the seismic-risk analysis or seismic-hazard analysis.

SEISMOTECTONIC ZONE, SEISMOTECTONIC

PROVINCE - A seismogenic zone in which the tectonic processes causing earthquakes have been identified. These zones are usually fault zones.

SOURCE VARIABLE - a variable that describes a physical characteristic (e.g. magnitude, stress drop, seismic moment, displacement) of the source of energy release causing an earthquake.

STANDARD DEVIATION - the square root of the variance of a random variable.

UPPER BOUND - see "Maximum Possible."

VALUE AT RISK - the potential economic loss (whether insured or not) to all or a certain subset of structures as a result of one or more earthquakes in an area. See "Exposure."

VARIANCE - the mean squared deviation of a random variable from its average value.

VULNERABILITY - the degree of loss to a given element at risk, or set of such elements, resulting from an earthquake of a given magnitude or intensity. which is usually expressed on a scale from 0 (no damage) to 10 (total loss). 